\title{
ASSESSING THE IMPACT ON PEFR AMONG SMOKERS AND PASSIVE SMOKERS-A COMPARATIVE STUDY
}

\author{
GANESH PANDIAN B.1,2*, SIREESHA P.1, YEN PING N. G. ${ }^{1}$, SUSMITHA G. ${ }^{2,3}$, SAM AASEER T.1
}

1Unit of Clinical Pharmacy and Pharmacy Practice, Faculty of Pharmacy, AIMST University, Malaysia, ${ }^{2}$ Department of Pharmacy Practice, Shri Vishnu College of Pharmacy, Andhrapradesh, India, ${ }^{3}$ Bhaskar College of Pharmacy, Moinabad, India

Email: ganeshhhh1@gmail.com

Received: 24 Jul 2019, Revised and Accepted: 30 Sep 2019

\section{ABSTRACT}

Objective: The purpose of this study was to monitor the intensity and difference in Peak Expiratory Flow Rate (PEFR) between smokers and passive smokers.

Methods: A total of 1000 participants were enrolled in two groups as smokers and passive smokers who are living closely with smokers. Their PEFR values were measured with Wright's mini peak flow meter. The influence of smoking on the lung function among smokers and passive smokers were assessed with a suitable statistical test.

Results: Among the study participants, most of the smokers were in the age group of 31 to 60 and 31 to 50 in passive smokers. Based on the lung function smokers (31\%) and passive smokers (19.2\%) were in the red zone, PEFR was decreased in both smokers as well as passive smokers, and the magnitude of decline was higher in passive smoking elderly individuals. The impact of passive smoking was significantly observed in all the categories of smoking history they are living with.

Conclusion: Smokers and passive smokers have equally deleterious effects on PEFR. Where passive smoking emerged as the main variable to influence airway obstruction in smokers that caused a greater reduction in PEFR.

Keywords: Respiratory Function Tests, Peak Expiratory Flow Rate, Smoking

(C) 2019 The Authors. Published by Innovare Academic Sciences Pvt Ltd. This is an open-access article under the CC BY license (http://creativecommons.org/licenses/by/4.0/) DOI: http://dx.doi.org/10.22159/ijpps.2019v11i11.35058

\section{INTRODUCTION}

Tobacco use is the leading cause of death and according to the WHO report on the global tobacco epidemic, in 2017 there were 2.7 billion people still lacking protection from the illness, disability, and death caused by tobacco use and second-hand smoke exposure [1]. WHO estimated that almost one-half of the world's children (nearly 700 million) are exposed to tobacco smoke from the adults, where the major exposure takes place at home [2]. About 40\% of children, 33\% of male non-smokers and $35 \%$ of female non-smokers were exposed to second-hand smoke in 2004 globally [3].

Passive smoking or environmental tobacco smoke (ETS) exposure has been variously described as 'second-hand smoke' or 'involuntary smoking'. An exhaustive report on health consequences of involuntary smoking highlighted the increased risks of several diseases similar to those seen among smokers; in persons exposed to ETS at home or a workplace [4]. There are very few reports on the health effects of ETS from the developing and the underdeveloped countries. Children exposed to second-hand smoke may lead to respiratory illnesses as a result of adverse effects on their immune system and lung growth and development [5].

Passive smoking exposure was estimated worldwide to have caused deaths from ischemic heart disease, lower respiratory infections, asthma, and lung cancer, there were $6,03,000$ deaths attributable to it in 2004 which was about $1.0 \%$ of worldwide mortality [3]. It was reported that the increasing risk and dose relationship for respiratory symptoms related to total ETS exposure [6] which has been estimated that second-hand smoke is responsible for each year 22,000 hospitalizations between $1,50,000$ and $3,00,000$ cases of bronchitis and pneumonia and between 8,000 and 26,000 cases of asthma [7].

Tobacco smoking is a major risk factor for cardiovascular disease, COPD, and some cancers [8] where the morbidity and mortality with tobacco use is entirely preventable. The death toll from tobacco use is projected to rise worldwide from 5.4 million in 2004 to 8.3 million in 2030 [9]. Tobacco smoking in Indian males is much higher (19\%) than females (2\%) and $38.7 \%$ of adults were exposed to secondhand smoke at home according to Global Adult Tobacco Survey 2 (GATS 2) India 2016-17 Report [10]. It is interesting to note that though the prevalence of cigarette smoking in rural areas is lower than in urban areas, the number of cigarette smokers in rural areas are higher than in urban areas.

Several studies have reported that PEFR was significantly lowered in smokers than in non-smokers and some studies found a maximum reduction in PEFR among beedi smokers than cigarette smokers. High prevalence for both cigarette and cigar smoking in the region, inconsistent findings, and the lack of literature relating the smoking and PEFR prompted us to take up the present study [11]. The objective of the study was to investigate the extent of PEFR affected among smokers and passive smokers.

\section{MATERIALS AND METHODS}

All the study procedures were performed with the approval of the Institutional Research Council and the Institutional Human Ethics Committee (Protocol number: 5/PD1). The study population was selected irrespective of gender and age with the written consent to participate in this study. The study participants were categorized into two groups as smokers and passive smokers. Smokers were recruited based on their self-reported smoking status and the person living with the smokers; who don't smoke were included in passive smokers group based on their exposure to smoke. A total of 500 smokers and 500 passive smokers were included as quota sampling.

The respiratory problems, peak flow rate and their knowledge on passive smoking were assessed; the data were collected from the participant and then entered in a pre-designed data collection form which includes participant's demographics such as age, smoking status, history and details of respiratory problems. The individual 
peak expiratory flow rate was measured using Wright's peak flow meter [12]. Peak expiratory flow rates for two different groups such as smokers and passive smokers were assessed individually.

In this study, peak flow meter was used to assess the peak expiratory flow rate. The subject was allowed to stand in an upright position and the meter was placed horizontally in front of the mouth. At first, the subject was allowed to take a deep breath in by firmly closing the lips around the mouthpiece making sure that there is no leakage of air around the lips and is allowed to breathe out the air as fast as possible. Cursor reading [PEFR value] was recorded and the cursor was reset to zero and the same above procedure was repeated for two more times for obtaining the total three readings. Subjects were categorized into three different zones based on the markings and readings of the peak flow meter. The PEFR value of $150-250 \mathrm{l} / \mathrm{min}$ was considered as red zone (danger zone) indicating that the participant is in high risk, yellow zone (caution zone) with PEFR value of $250-350 \mathrm{l} / \mathrm{min}$ signals caution the narrowing of airways and green zone (clear zone) with PEFR value more than 350 $1 /$ min indicates normal peak flow.

All the data were entered in Microsoft Excel and analyzed using Graph pad prism version 7.0. Continuous variables (age, smoking history, PEFR) were represented as mean \pm Standard Deviation and categorical variables (educational level, respiratory problems) were represented as frequency (\%). To evaluate the impact of smoking and passive smoking on lung function Pearson correlation analysis was done.

\section{RESULTS AND DISCUSSION}

Passive smoking is known to be deleterious for human health as compared with first-hand smoking, especially the respiratory system; therefore it is important to identify the risk for individual second-hand smokers and to create awareness among them. This study is conducted to create awareness among passive smokers about the risk involved and how to avoid it by assessing their knowledge about passive smoking. A total of 1000 subjects were included in the study classified according to their self-reported status as smokers $[n=500]$ and passive smokers $[n=500]$. The subjects included as passive smokers were those who were exposed to cigarette smoke at home or the workplace. All the study subjects for passive smoking and the non-smoking group were female and the cause of passive smoking is by their husband.

Age-wise distribution among the study participants shows most of the smokers [54.2\%] are in between 31-60 y of age, most [59\%] of the passive smokers are in between $31-50$ y of age. Previously conducted research shows that there was the highest prevalence reported in men aged 40-49 y [12]. Among the study participants $31 \%$ of smokers, $19.2 \%$ of passive smokers were in the red zone [PEFR = 150-250 l/min] indicating abnormal lung function, which shows the extent of the problem among the smokers and passive smokers. Previously conducted research shows that cigarette smoking or exposure to it had an impact on PEFR $[11,14]$.

Table 1 shows the impact of smoking on lung function among smokers and passive smokers who are staying with them. The study result shows that increasing smoking history is strongly associated with the decrease in PEFR for both the smokers and passive smokers, which is probably because the variable was dependent on the expiratory effort and the elastic recoil of the lungs and the airway size, factors which are known to reduce with advancing age. Also, there may be possible reasons for the decrease in PEFR as inflammation which is common and a constant pathological finding in cigarette smokers and the gender and age-related effect. Previously conducted research shows that there exists a strong correlation between the intensity of cigarette/cigar smoking and PEFR i.e. the greater the intensity of cigarette/cigar smoking, the lesser the PEFR value [11]. Smoking is a very well-known cause for conditions such as emphysema, COPD and chronic bronchitis; where the risk increases with the pack-years [15]. Smokers have a steeper decline in FEV1 who on average had a decline of 25-30 ml a year [16]. It should be taken into consideration also the extent of the passive smoker's lung function decline. In this study, the impact of smoking on lung function is almost equal in passive smokers like smokers which bring in a major concern for the involuntary smoking group also. It is important to note that the chances for second-hand smoke exposure are high in home than any others (such as workplace, restaurants, public transportation, etc.), [10] there is a need to bring in the awareness among the smokers and also their family members, which can avoid the chances for the passive smoking exposure.

Table 1: Impact of smoking on lung function (PEFR)

\begin{tabular}{|c|c|c|c|c|c|c|}
\hline \multirow{2}{*}{$\begin{array}{l}\text { Smoking } \\
\text { history (years) }\end{array}$} & \multicolumn{3}{|l|}{ Smoker $(n=500)$} & \multicolumn{3}{|l|}{ Passive smoker $(n=500)$} \\
\hline & PEFR (1/min) (mean \pm SD) & $\mathbf{R}^{2}$ & p value ${ }^{\ddagger}$ & PEFR (1/min) (mean \pm SD) & $\mathbf{R}^{2}$ & p value ${ }^{\ddagger}$ \\
\hline $1-10$ & $346 \pm 62.78$ & 0.06827 & $0.0004^{*}$ & $308 \pm 48.01$ & 0.08044 & $0.0001^{*}$ \\
\hline $11-20$ & $291.4 \pm 57.04$ & 0.02726 & $0.0390^{*}$ & $295.7 \pm 48.07$ & 0.03858 & $0.0100^{*}$ \\
\hline $21-30$ & $269.7 \pm 56.47$ & 0.1248 & $0.0027^{*}$ & $266.1 \pm 53.99$ & 0.08905 & $0.0121^{*}$ \\
\hline $31-40$ & $249.2 \pm 60.33$ & 0.1356 & $0.0078^{*}$ & $246.6 \pm 50.01$ & 0.08905 & $0.0327^{*}$ \\
\hline $41-50$ & $229.2 \pm 57.51$ & 0.2616 & $0.0054^{*}$ & $224.5 \pm 21.38$ & 0.3868 & $0.0004^{*}$ \\
\hline
\end{tabular}

${ }^{*} \mathrm{p}<0.05^{\sharp}$ Pearson correlation analysis

\section{CONCLUSION}

There are deleterious effects on lung function among both the smokers and passive smokers causing a reduction in PEFR. Passive smokers also have equal harms as compared to first-hand smokers, which brings the need to be cautious in the environment. Considering this the health policies may be adopted by banning smoking in public places.

\section{FINANCIAL SUPPORT AND SPONSORSHIP}

$\mathrm{Nil}$

\section{AUTHORS CONTRIBUTIONS}

All the authors have contributed equally

\section{CONFLICTS OF INTERESTS}

All the authors declare no any conflicts of interest

\section{REFERENCES}

1. World Health Organization (WHO) report on the Global Tobacco Epidemic; 2017. Available from: http://www.who.int/ tobacco/global_report/en/. [Last accessed on 20 May 2018]

2. Avsar A, Darka 0, Topaloglu B, Bek Y. Association of passive smoking with carries and related salivary biomarkers in young children. Arch Oral Biol 2008;53:969-74.

3. Oberg M, Peruga A, Pruss Ustun A, Sjaakkola M, Woodward A. Worldwide burden of disease from exposure to second-hand smoke: a retrospective analysis of data from 192 countries. Lancet 2011;377:139-46.

4. Office on Smoking and Health (US). The Health Consequences of Involuntary Exposure to Tobacco Smoke: A Report of the Surgeon General. Atlanta (GA): Centers for Disease Control and Prevention (US); 2006. Available from: https://www.ncbi. nlm.nih.gov/books/NBK44324/. [Last accessed on 10 Mar 2018]

5. US EPA. Respiratory health effects of passive smoking: lung cancer and other disorders. U. S. Environmental Protection Agency, Office of Research and Development, Office of Health 
and Environmental Assessment, Washington, DC, EPA/600/690/006F; 1992.

6. Jansson C, Chinn S, Jarvis D, Zock JP, Toren K, Burney P. Effects of passive smoking on respiratory symptoms, bronchial responsiveness, lung function, and total IgE in the European Community respiratory health survey: a cross-sectional study. Lancet 2001;358:2103-9.

7. What's new in nicotine and tobacco research? Nicotine Tobacco Research 2003;5:281-7. Available from: https://doi.org/ $10.1080 / 1462220031000095717$ [Last accessed on 10 Jul 2019].

8. Nida BSA, Natasha H, Nahlah EI. Smoking status affecting survival of adenocarcinoma lung cancer patients in Kuala Lumpur, Malaysia. Asian J Pharm Clin Res 2017;10:312-3.

9. Mathers CD, Loncar D. Projections of global mortality and Barden of disease from 2002 to 2030. Plos Med 2006;3:e442.

10. World Health Organization, CDC. Global Adult Tobacco Survey 2 (GATS 2): India factsheet; 2016-2017. Available from: http://www.who.int/tobacco/surveillance/survey/gats/GATS_
India_2016-17_FactSheet. pdf?ua=1. [Last accessed on 10 Jun 2018].

11. Tambi M, Rao BN, Glad MMI, Praveen KM. Effect of cigar and cigarette smoking on peak expiratory flow rate. J Clin Diagnostic Res 2013;7:1886-9.

12. Wright BM, McKerrow CB. Maximum forced expiratory flow rate as a measure of ventilatory capacity: with a description of a new portable instrument for measuring it. $\mathrm{Br}$ Med J 1959;2:1041-6.

13. Omair A, Kazmi T, Alam S. Smoking prevalence and awareness about tobacco related diseases among medical students of Ziauddin Medical University. J Pak Med Assoc 2002;52:389-92.

14. Jain SK, Rajendra K, Sharma DA. Factors influencing peak expiratory flow rate in normal subjects-II. Lung India 1983;1:92-7.

15. Forey BA, Thornton AJ, Lee PN. Systematic review with metaanalysis of the epidemiological evidence relating smoking to COPD, chronic bronchitis and emphysema. BMC Pulm Med 2011;11:36. 